\title{
Building a cyber-museum of early instruments and procedures with the 1903 Eduard Zimmermann Catalog as an example
}

\author{
EDWARD J. HAUPT \\ Montclair State University, Upper Montclair, New Jersey
}

\begin{abstract}
The rationale and methodology for the construction of a Web site using images from a 1903 German (Leipzig) equipment manufacturer, Eduard Zimmermann, are presented. Many of the illustrations cite Wundt's work. Topics in the construction of such a site are integrated through the proposal for a database standard for sites displaying older equipment. Methods for the efficient construction of such a site, including translation problems and a database catalog for images and captions to permit easier creation of HTML files, are included. Present and future uses of the site, including evaluation of the historical importance of the catalog and relation to other sites concerned with the history of experimentation, are presented.
\end{abstract}

Psychological science is unique in that a subdiscipline of philosophy leapt from being largely anecdotal and "armchair" to become an established, individual natural science in the 30 years between 1880 and 1910. The experimentation of this new discipline, as well as its methodological basis, was directly taken from physiology, but new methods, requiring new apparatus, were developed with great rapidity in that brief period. There are better and worse information sources for that period, but none, to my mind, establish the rapid growth of experimentation with adequate attention to the sequence of its details and conceptual advances. Thus, in many ways, this development of experimentation that led to the field of experimental psychology has never been adequately presented or documented. The methods described in this paper should assist in the provision of better information about the growth of experimental methods and provide assistance to research in the history of experimentation.

The equipment used by early experimenters was mechanical and sometimes electromechanical. The existence of computers with high-resolution screens and the possibility of precise color displays have rendered almost all of this older equipment obsolete. Thus, we are faced with both a loss of knowledge of how to operate equipment designed as recently as the $1960 \mathrm{~s}$ and an almost complete absence of people who know how to operate the equipment used before 1960 (equipment that was often powered by spring and/or weight motors).

The creation of the Web site for the cyber-museum has been carried out in collaboration with Thomas B. Perera of Montclair State University. This manuscript is an extensively modified version of a paper presented at the annual meeting of the Society for Computers in Psychology (SCiP), Philadelphia, November 1997. Correspondence should be addressed to E. J. Haupt, Department of Psychology, Montclair State University, Upper Montclair, NJ 07043 (e-mail: haupt@email.njin.net).
There exists, however, a great opportunity to codify knowledge of early experiments and to link it to images of the equipment through the Internet. Some examples of such cyber-museums (e.g., Balsam \& Perera, 1997; Haupt \& Perera, 1997; Irtel, 1995; Pataloney \& Creelman, 1997) exist. This paper proposes standardization of such projects, as well as a preliminary standard that would ensure fruitful interchange of information.

\section{INFORMATION AND IMAGE SOURCES}

\section{Locating Important Images}

The beginnings of experimentation were tightly connected to the apparatus used; however, few contemporary experimental psychologists know the locations of images of early psychological experiments or of the existence of facsimile editions of early catalogs (Zimmermann, Stoelting, etc.). In addition, almost no American psychologist can read the German book that explicitly describes the equipment collected at the University of Heidelberg (Gundlach, 1986), which provides the most comprehensive descriptions of such equipment. Because book illustrations were generally limited for a variety of reasons, catalogs are the main sources of images and descriptions of early psychological apparatus. On FirstSearch (a widely used library search program), I found no copies of the Eduard Zimmermann catalog (Zimmermann, 1903/1983) when I searched for either "E Zimmermann" or "psychological apparatus," although I did not search German libraries. I found three copies of the 1908 Spindler and Hoyer catalog (which has not been reprinted), and I found one copy of the facsimile of The Great Stoelting Catalog of 1930 (Stoelting, 1930/1997)-that was, however, in the Library of Congress, from which it could not be loaned.

A second major source of images of early equipment is found in the old equipment itself. Although many German laboratories were destroyed during World War II, 
there are a number of laboratories outside of Germany, such as those in Belgrade, Graz, and Leuven, which contain extensive collections of equipment but which are primarily the responsibility of the local department and thus do not have curators or complete descriptions. For any of these pieces of equipment, only a good photograph is required.

\section{Displaying and Understanding the Devices}

A small cyber-museum, which serves as a model of this activity and shows and explains the devices in the Eduard Zimmermann catalog as historical objects, has been created (Haupt \& Perera, 1997). Since even copies of facsimile catalogs in general and this one in particular are not widely held by libraries, the site provides an important service to the psychological community. It allows visitors to see the similarities and the differences of old equipment and our present apparatus. As at any net site, the images are available at any time of the day from any place in the world. In addition, e-mail messages can be left for the curator(s) by any person seeking additional information. Furthermore, since the catalog was written in German, the cyber-museum provides images and explanations, in English, of a number of devices that have been important in the history of psychology and locates them more closely to the time when they first became available.

Understanding the function and use of the apparatus from the catalog remains problematic. Little is known about the early history of the firm or of its connection to Wundt (Haupt, 1997), although Wundt's Grundzüge are often cited as sources. Since most images illustrate components, there are very few sources from which we can get a good idea of the way in which combinations of these devices (almost all of the illustrations are of components) were used in experiments. Most of the experiments were published in German journals, and very few articles have illustrations of their apparatuses. Titchener $(1901,1905)$ has many illustrations and descriptions of methods, but Titchener often expressed himself in ways that are now difficult to understand. I do not wish to malign Woodworth (1938), but in his examination of three procedures of G. E. Müller, I have found what I regard as grave deficiencies in his accounts of Müller's important methodology (e.g., Haupt, in press, for accounts of psychophysics and, particularly, of the important memory procedures in the 1894 paper by Müller and Schumann). Since Woodworth was one of the few Americans who had extensive knowledge of German and German procedures, this creates undeniable problems for the history of early experimentation. The one incontrovertibly fine methodologist who wrote extensively of these procedures (still, with few illustrations) was Joseph Fröbes, who studied both with Müller and with Wundt. Unfortunately, Fröbes's $(1917,1920)$ volumes were never translated. Thus, we must accept that a clear understanding of these German procedures will require careful scholarship in the future.

\section{Images and Copyright Restrictions}

Much of the material for such a museum is surprisingly immune to copyright restrictions. A general rule is that anything 75 years old is no longer under copyright. Thus, book images and photographs and parts of journal articles that were published before 1923 are all fair game. While newer catalogs may still be subject to copyright, the manufacturers (some of whom still exist, such as Stoelting, $1930 / 1997$, and Spindler \& Hoyer, 1908) are unlikely to be interested in images of equipment that they no longer sell, and they may appreciate the extra publicity that ensues.

In addition, photographs that you make are your property. Should you find an old, but important, piece of apparatus in your laboratory or in a museum, with permission you are free to make pictures of it and use it in a site.

\section{Scanning the Images}

It was first necessary to make the images ready for the museum. The original images are basically $5 \times 8 \mathrm{~cm}$ illustrations on the catalog page (although some are $2 \times$ $8 \mathrm{~cm}$ ), printed from woodcuts or steel etchings (or electrotypes made from such originals). The images have varying line densities extensively used as shading devices. Scanning was done by simply preparing the images as gif files. Most likely, any scanner that can take the images as $200 \times 200$ or $300 \times 300$ dpi scans will be satisfactory for many applications. Such images look good in internet viewing but might be insufficiently detailed for preparing transparencies. In addition, higher resolution (e.g., $600 \times 600 \mathrm{dpi}$ ) images are necessary, and they should be available for downloading. Photographic images should meet professional standards and should be available in gray scale. To see what the illustrations look like, a Wundt "fall" tachistoscope, most often used in Leipzig for class demonstrations, is shown as Figure 1.

For many purposes, line art illustrations, without shading, would be more useful didactically (many American apparatuses are so illustrated in the Stoelting catalog). Catalog images or photographs, unfortunately, with extensive shading, cannot easily be turned into line art, which would be better for illustrations. Many of these images must therefore be .bmp images. Line drawings-which, for example, CorelDraw does poorly for such imagesrequire artist's techniques, such as outline tracing from an enlarged photocopy. Subsequently, the photocopy of the outline tracing can be scanned as line art. However, reconstructions of the geometric shapes from a threedimensional drafting program would be even better and could provide line drawings that could be rotated.

\section{A DATABASE METHODOLOGY FOR AN IMAGE-BASED NET SITE}

The present paper has been prepared partly to present a methodology of efficiently displaying cyber-museum collections and partly to propose a standard method that 


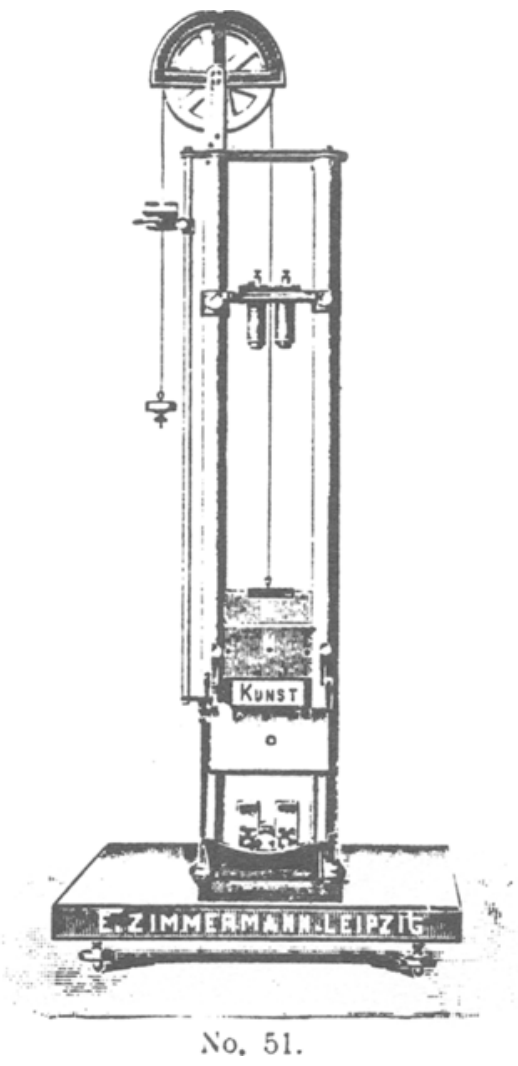

Figure 1. Illustration of the Wundt "fall" tachistoscope. By the time the catalog was published, the Erdmann and Dodge tachistoscope, which provided more precise timing and illumination, was well known (but not included in this catalog). Thus, this apparatus is for demonstration and not for research. On the illustration, you can see the label E. Zimmermann. This is clearly an addition to an older steel engraving plate.

would facilitate the interlinking of such museums and descriptions of early experiments. The following material describes both the content and database use for such sites. The database fields are shown in the Appendix.

A simple (flat-file) database, constructed as a Word Perfect secondary merge file has provided answers to many site construction problems. The materials to explain a Web site are similar to library catalogs, but they are also something more. Thus, it seemed important to me to prepare the materials in a form that could serve as pointer to an item in any other catalog, whether the item was the original source or an image in a library specializing in such images. For these images, however, the explanations are more detailed than are typical of library catalog entries and are more similar to the abstracts of articles.

\section{Preparation of the Text Materials}

Translation of the item descriptions of the Zimmermann catalog from German was not particularly complicated. With the possible exception that "Deprez" meant the French engineer Marcel Deprez, and not some Ger- man variant of depression, and the discovery that Hämodromograph (a blood velocity meter) could still be found in medical dictionaries as "hemodromograph," title translation seemed relatively easy.

One of the most critical aspects of cyber-museums is the texts that explain these images. As noted before, Titchener $(1901,1905)$ and even Woodworth (1938) can be unreliable guides, and Titchener's descriptions could be used without copyright problems. At the present time, very few people understand how the apparatus was used, since few people trained after World War II (except, perhaps, in Germany) were trained with examples of such spring-motor-driven mechanical apparatuses. For example, when I visited the Leipzig Physiological Institute, the person who took care of its older apparatuses did not recognize that he was responsible for a late model Baltzarstyle kymograph, a model that was standard for instruction in physiology until after World War I.

The explanatory texts, however, were another matter. As I have indicated, some of the uses of these apparatuses are obscure, even to present researchers who learned experimental technique in the 1940s or 1950s when these devices or similar ones were still present in many laboratories. Thus, it was not clear that a simple translation would describe the apparatus well, since the descriptions were written for practicing physiologists and psychologists in 1903. Translations, too, are often difficult to render precisely and are thus unproductively time consuming.

I therefore decided to make short captions that would describe the apparatus and its uses in a contemporary manner. This allows us to add comments that come from other sources (e.g., an obituary for Carl Marbe stated that his color-mixing demonstrator-see Zimmermann, 1903/1983, Figure 14 - had been used after World War II. For many people, this is a good level of description, particularly for new history students who, without much science background, are starting to do work in the history of medical and psychological sciences. I view these people and psychologists who teach the history of psychology (who often have little experimental psychology training) as a primary audience for these materials.

Another problem is that some terminology is not easily found even in a large modern German dictionary such as the Duden Universalis. Fortunately, for a word such as Fournierholz (inlay wood), a term used to describe the membrane of a voice-activated switch, there is a GermanEnglish technical dictionary from the 1920s. Thus, several obscure words were found. Another useful source of information about these devices has been Tigerstedt's (1904/1906) A Textbook of Human Physiology.

\section{Creation of Threads for the Site}

By itself, a collection of images does not create a useful display format. The translations of the captions, descriptions of the apparatuses, preparation of hypertext files, and connecting the illustrations to libraries all produce difficulties. Because the Zimmermann catalog contains about 160 images, we wished to make threads that 


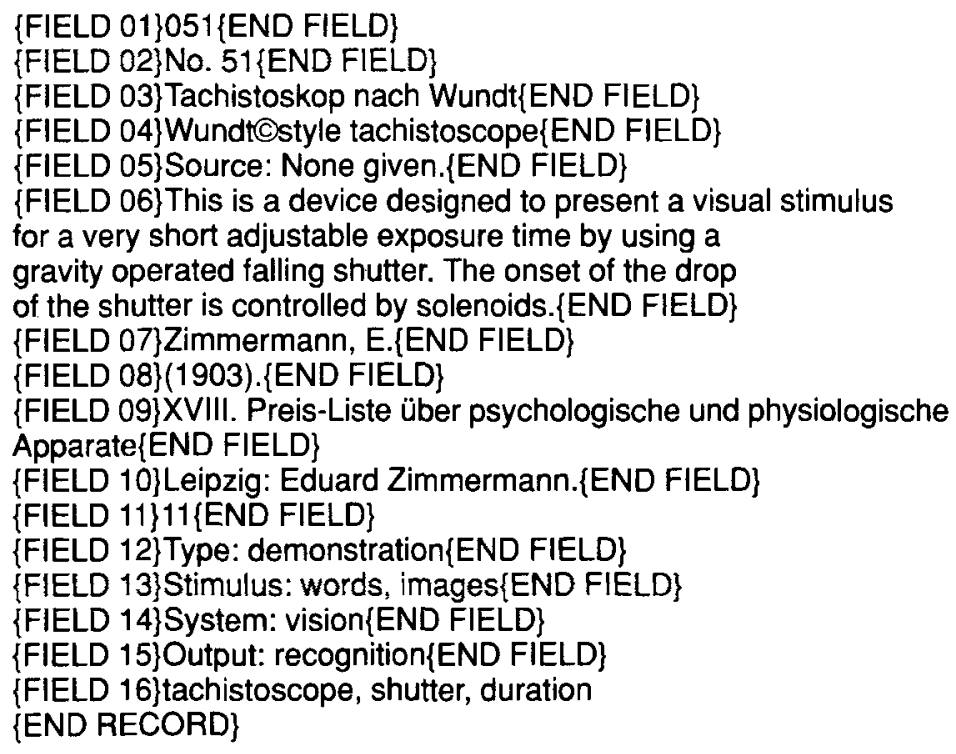

Figure 2. WordPerfect 5.1 secondary merge file used to provide data about the Wundt fall tachistoscope shown in Figure 1. Field 6 contains the description of the apparatus written by the author, and fields 7-10 contain an APAstyle citation of the source. Fields 12-15 show the categorization system used to form threads for the site.

show important aspects of the set of illustrations. Many of these difficulties were solved by simple database methods presented here.

I attempted to use the Medical Subject Headings (MESH) characteristics, of which the Dittrich Library in Indianapolis kindly sent me a copy, to create descriptive categories. Unfortunately, they did not suffice. Now, I use a somewhat more detailed structure that can be used for the purpose of forming threads (which are described below). At this point, we are still constructing a series of threads to help visitors find their way through the images in an intelligible way. To do this, four categories of possible descriptions have been added to the records, which provide the following categories: (1) (general) type, which separates objects into components, demonstration apparatus, and research apparatus (this seems important to me, since surprisingly few of the images qualify as research quality); (2) stimulus, which describes the sensory modality for which the stimuli are effective, including visual, auditory, and tactile; (3) psychological system, which specifies the response type including visual auditory, motor, and tactile; and (4) output, which specifies the type of recording that a component enables.

Since these characterizations are part of a database (merge) file, the creation of threads is made easier by sorting the files in order of these characterizations, sources, and so on, and using these as the basis of threads through the site.

\section{Relation to Existing Library Catalogs}

Whenever you make use of a library catalog for a citation, there is an explicit structure to these records, known as machine-readable cataloging (MARC). Historical citation requires the separation of the current source from the original source. Since the original source is largely inaccessible, it is necessary to include the original source in order to assist in preparing a proper scholarly citation. The linking of the records to library records by including MARC fields in the database for the source (Zimmermann, 1903/1983) as well as the page and object number is thus made possible. Linking of these images to other sources is thus made possible by including MARC-type source information.

\section{Keyword Identifier}

Since some search engines limit their identification to the contents of the HTML file header, a further field is required to assist searches on the World-Wide Web. Since no other field in the database contains only keyword identifiers, a further field was added. The contents of this field are thus inserted into the header field of each image from field 16.

\section{Database Solution to Problems of Identification and Organization}

The entries were first prepared with a rather simple (flat-file) structure, consisting of illustration number, German title, English (translated) title, description (in English), page number, and the items required for a citation. This provided the first version of the site, but one that we have found to be limited.

For such materials, the choice of database can be important. Databases that were developed primarily for relational work (e.g., Dbase III, Paradox, and Access) often handle large text fields (i.e., descriptions) poorly. Thus, 
HTML><! COPYRIGHT (c) 1998-expanded captions, Edward J. Haupt:

November 16, 1997; keywords: FIELD(16)>

$<\mathrm{HEAD}>$

$<$ TITLE $>$ FIELD $(4)</$ TITLE $>$

$</ H E A D>$

$<B O D Y>$

<img ALIGN=left srC="x_FIELD(1).gif" >

$<\mathrm{H} 2>\mathrm{FIELD}(4)<\mathrm{H} 2>$

$<\mathrm{p}>$

$($ FIELD(3)) <BR>

Description: FIELD(6) Description Copyright 1997, Edward J.Haupt.<BR>

(Field(5)) <BR>

Source of illustration: FIELD(7) FIELD(8)<i>FIELD(9)<i> (p. FIELD(11)).

$\operatorname{FIELD}(10)<p>$

DESCRIPTORS: $<B R>$

FIELD $(12)<B R>$

FIELD(13) <BR>

$\operatorname{FIELD}(14)<B R>$

$\operatorname{FIELD}(15)<B R>$

$<p>$

$<A$ href="museum.html" $>$ Go back to main museum page. $</ A>$

$</ B O D Y>$

$</ \mathrm{HTML}>$

Figure 3. The WordPerfect 5.1 file used as a primary merge file for the generation of HTML files for display of the objects. Generation of a large word-processing file from this primary merge file and data (secondary merge) files can be saved as an ASCII (DOS) file and can subsequently be quickly imported into a Web site.

for these purposes, the secondary merge file of a word processor (e.g., WordPerfect) worked better. These text materials were prepared as a secondary merge file using Word Perfect 5.1, although any secondary merge format, spread sheet, or flat-file database might be appropriate, and any of these are mutually transferrable.

\section{Database Records to HTML Files}

The creation of the individual Web pages for each image was accomplished with a merge file, containing primarily HTML codes, into which the appropriate elements for each image (title, German title, image identification number, characterization, etc.) were brought by using the merge feature of WordPerfect. A sample database record for Wundt's tachistoscope is shown in Figure 2, and the primary merge file is shown in Figure 3.

The use of a single merge file enabled construction of the required.HTML pages rather easily. The primary merge file contained all the repetitive .HTML codes required for each image. The English title could be placed at the top, and the German title followed. Their sizes were made standard, and a pointer to the appropriate image file was constructed automatically. Thus, the WordPerfect merge feature was used with the two files, and the resulting file was saved. An ASCII editor (in this case, the WordPerfect 6.0 ASCII editor) was then used to cut apart the components for each file. A page of the ASCII file was blocked and moved to a blank workspace, with a keystroke macro. The block was then made into a separate HTML file by giving it the correct name and extension. The HTML files for the first 80 images thus only required about $2 \mathrm{~h}$ to prepare. It is desirable to create such separate links, since this makes it necessary for only a small file to be transported on the net.

\section{Providing Links to Accounts of Experiments}

An important purpose that might be added to these museums is to show the connections of the apparatuses with the experiments in which they were used. Therefore, a field has been provided for each image, which can provide links to experimental descriptions.

\section{ADDING TO THE HISTORY OF EXPERIMENTATION}

The preceding description of a Web site for images of psychological apparatus (Haupt \& Perera, 1997) shows that useful information-collateral to the contents of published research and important for an understanding of the history of psychological instrumentation - can be readily presented through a Web site. The practical uses of such a Web site, the database methodology, a database structure, and the role of this Web site in improving knowledge of the history of psychological experimentation have been discussed.

Although the great bulk of early innovation occurred in German-speaking lands, there are many important early research studies available in English. We underestimate Galton's (1883) studies (most of which were published in the 1870s) and their importance for later experimentation. Some American students' dissertations (e.g., Cattell, 1947, which was also published in Mind) have been translated. 
In addition, there are many studies in early issues of the American Journal of Psychology, Psychological Monographs, and the Psychological Review. As an example, Mary Whiton Calkins (e.g., Madigan \& O'Hara, 1992) is often credited with the first use of a paired-associate methodology. However, there is no study that examines this methodology in detail and the similarity of these procedures to the later standard methods for paired associates. In fact, when Tolman did his dissertation under Münsterberg (also Calkins advisor), Tolman used Müller's techniques and not Calkins's. The procedures of Ebbinghaus (1885/1909) are described in detail-we could easily make a computer simulation of the methods, from which we could see how different they are from any of the later standard methodologies.

The site has quickly become known to people interested in early equipment. In addition, the images have been used as the basis of discussions on the rete (rete@maillist. ox.ac.uk), which provides additional information.

Thus, the existence of this museum site permits the linking of the equipment images and provides descriptions to summaries of early experiments. Rapid access to equipment summaries is made possible through a standard database format and keyword linkages. The information contained provides a powerful addition to our knowledge of early equipment. The beginnings of experimentation in psychology are thus provided with a fundamental resource for the elaboration of the largely unknown early history of such experimentation.

\section{REFERENCES}

Balsam, P., \& Perera, T. B. (1997). Barnard College history of psychology collection [Hypertext document]. Available: http://www.columbia.edu/barnard/psych/b_museum.html

CATTELL, J. M. (1947). On the time required for recognizing and naming letters and words, pictures and colors (A. T. Poffenberger, Trans.). In A. T. Poffenberger (Ed.), James McKeen Cattell: Man of science (Vol. 1, pp. 13-25). Lancaster, PA: Science Press. (Original work published 1885)

EbBinghaus, H. (1909). Memory: A contribution to experimental psychology (H. R. Ruger \& C. Bussenius, Trans.). New York: Columbia University, Teachers College Press. (Original work published 1885)

FRöвES, J. (1917), Lehrbuch der experimentellen Psychologie (1. Ausg., Bd. I) [Textbook on experimental psychology (1st ed., Vol. 1)]. Freiburg im Breisgau: Herder.
FRÖBEs, J. (1920). Lehrbuch der experimentellen Psychologie (1. Ausg., Bd. II) [Textbook on experimental psychology (1st ed., Vol. 2)]. Freiburg im Breisgau: Herder.

GaLTON, F. (1883). Inquiries into human faculty and its development. New York: Macmillan.

GUNDLACH, H. (1986). Inventarium der alternen Experimentalapparate im Psychologischen Institut Heidelberg sowie einige historische Bemerkungen [Inventory of the older experimental apparatus in the Psychological Institute of the University of Heidelberg along with historical remarks] (2nd ed.). Heidelberg: Psychological Institute of the University of Heidelberg.

HAUPT, E. J. (1997). A brief history of the E. Zimmermann firm [Hypertext document]. Available: http://www.chss.-montclair.edu/psychology/museum/zimmfirm.html

HAUPT, E. J. (in press). G. E. Müller as a source of American psychology: The Zur Grundlegung der Psychophysik [On the foundations of psychophysics] and Untersuchung des Gedachtnisses [Investigation of memory]. In R. W. Rieber \& K. Salzinger (Eds.), Psychology: Theoretical and historical perspectives (rev. ed.). Washington, DC: American Psychological Association.

Haupt, E. J., \& Perera, T. B. (1997). The E. Zimmermann apparatus catalog of 1903 (Hypertext document]. Available: http://www.chss. montclair.edu/-psychology/museum/museum.html

IRTEL, H. (1995). Historical color systems and images [Hypertext document]. Available: http://www.uni-mannheim.de/-unima/fakul/ psycho/irtel/colsys.html

MADIGAN, S., \& O'HARA, R. (1992). Short-term memory at the turn of the century: Mary Whiton Calkins' memory research. American Psychologist, 47, 170-174.

Pataloney, D. W., \& Creelman, D. (1997). University of Toronto Museum of Psychological Instruments [Hypertext document]. Available: http://www.psych.utoronto.ca/museum/.

SPINDLER \& HOYER (1908). Apparate für psychologische Untersuchungen: Katalog 21 [Apparatuses for psychological investigations: Catalog 21]. Göttingen: Author.

C. H. Stoelting Co. (1997). The great catalog of the C. H. Stoelting Company, 1930-1937: A facsimile reproduction. Delmar, NY: Scholars Facsimiles and Reprints. (Original work published 1930)

TIGERSTEDT, R. (1906). A textbook of human physiology (J. R. Murlin, Trans.). New York: Appleton. (Original work published 1904)

Titchener, E. B. (1901). Experimental psychology (Vol. 1, Pt. 2). New York: Macmillan.

TITCHENER, E. B. (1905). Experimental psychology (Vol. 2, Pt. 2). New York: Macmillan

WoODWORTH, R. S. (1938). Experimental psychology. New York: Holt. Zimmermann, E. (1983). XVIII. Preis-Liste über psychologische und physiologische Apparate [18th price list of psychological and physiological apparatus]. Leipzig: Author. (Faksimilenachdruck 1983: FIM-Psychologie Modellversuch, Universität Erlangen-Nürnberg und Institut für die Geschichte der Neueren Psychologie, Universität Passau in Zusammenarbeit mit den Sondersammlungen des Deutschen Museums München.) Passau, Germany: Passavia Universitätsverlag. (Original work published 1903) 


\section{APPENDIX}

Database Fields for a Cyber-Museum

\{FIELD 01$\} 051\{$ END FIELD record identifier

\{FIELD 02\} No. 51 \{END FIELD figure (in text) identifier

\{FIELD 03\} Tachistoskop nach Wundt $\{$ END FIELD title of object [original language] \{FIELD 04\} Wundt-style tachistoscope \{END FIELD title of object [English]

$\{$ FIELD 05\} Source: None given. $\{$ END FIELD source/description of object and use from original text link to experiments which make use of objects

\{FIELD 06\} This is a device designed to present a visual stimulus

for a very short adjustable exposure time by using a gravity

operated falling shutter. The onset of the drop of the shutter is

controlled by solenoids. \{END FIELD $\}$ caption-description of object

\{FIELD 07\} Zimmermann, E. $\{$ END FIELD "author" of source

\{FIELD 08\} (1903). \{END FIELD\} publication date

\{FIELD 09\} XVIII. Preis-Liste über psychologische und physiologische Apparate\{END FIELD\} title

\{FIELD 10\} Leipzig: Eduard Zimmermann. END FIELD\} place: publisher

\{FIELD 11$\} 11$ END FIELD\} page no. in cited source

\{FIELD 12\} Type: demonstration \{END FIELD thread index no. 1: type

\{FIELD 13\} Stimulus: words, images $\{$ END FIELD $\}$ thread index no. 2: stimulus type

\{FIELD 14\} System: vision $\{$ END FIELD thread index no. 3: sensory or other psychological system

\{FIELD 15\} Output: recognition \{END FIELD thread index no. 4: type of (psychological) response)

\{FIELD 16\} tachistoscope, shutter, duration keyword(s) 